\title{
The role of PLGA/TPGS nanoparticle on xylazine-ketamine anesthetic activity in male albino rabbits
}

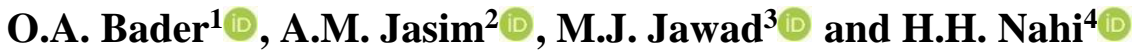 \\ ${ }^{1}$ Department of Surgery and Theriogenology, College of Veterinary Medicine, University of Mosul, Mosul, ${ }^{2}$ Department of \\ Physiology, Pharmacology and Biochemistry, College of Veterinary Medicine, Al-Qasim Green University, Babylon, \\ ${ }^{3}$ Department of Physiology, Pharmacology and Biochemistry, College of Veterinary Medicine, Karbala University, Karbala, \\ ${ }^{4}$ Department of Surgery and Obstetrics, College of Veterinary Medicine, Al-Qasim Green University, Babylon, Iraq
}

Article information

\section{Article history:}

Received March 07, 2021

Accepted July 11, 2021

Available online December 19, 2021

\section{Keywords:}

Vitamin E TPGS

Ketamine

Xylazine

Nanoparticles

PLGA

\section{Correspondence:}

O.A. Bader

omaralbader2003@uomosul.edu.iq

\begin{abstract}
D-a-tocopheryl polyethylene glycol succinate (Vitamin E TPGS or TPGS) has been approved by food and drug administration (FDA) as harmless adjuvant and is largely used in drug systems delivery. The aim of the study was to use the TPGS polymer as a drug release model to regulate the release of the anesthetic xylazine-ketamine in order to minimize therapeutically reference dose, avoid side effects, and improve efficacy. The study performed on 15 adult local breed male rabbits, divided into 3 groups with same number which injected intramuscularly with single dose of suggested anesthetics. Heart rate, respiratory rate, degree of muscle relaxation, onset of action and stages of anesthesia were evaluated, also induction of anesthesia, surgical anesthesia and recovery time were recorded. Nanoprecipitation technique was optimal method for preparing small particle size as well as reduce dose for therapeutic effect. Small and large dose was showed perfect analgesic and muscle relaxant activity of xylazine-ketamine drugs. Ketamine $30 \mathrm{mg}$ and xylazine $10 \mathrm{mg}$ loaded PLGA showed elevation of conciseness period as well as increase muscle relaxant. Ketamine $30 \mathrm{mg}$ and xylazine $10 \mathrm{mg}$ loaded PLGA reduce heart rate but onset of action delayed when compared with reference drug. The process of nanoprecipitation was ideal for forming small particle sizes and reducing the dosage for therapeutic effects. PLGA loaded with ketamine-xylazine demonstrated improved cycle concentration (walk time) as well as improved muscle relaxant, finally the protocol created an excellent anesthetic combination for induction of general anesthesia.
\end{abstract}

DOI: 10.33899/ijvs.2021.129688.1679, (CAuthors, 2022, College of Veterinary Medicine, University of Mosul.

This is an open access article under the CC BY 4.0 license (http://creativecommons.org/licenses/by/4.0/).

\section{Introduction}

The polymer is a macromolecule which consists of monomers called multiple repeating units. A copolymer is composed of two or more monomer of different forms. Glycolic and lactic acid are monomers of poly (lactic-coglycolic acid) (PLGA). The ratio of monomers can differ which had a significant influence on the copolymer 's properties (1). The FDA has given PLGA for utilizing outstanding properties such as biocompatibility, biodegradability and sustained release features a variety of medical (2). In last decate, its use as non-toxic biodegradable, and nonimmunogenic polymer for the progress controlled, and selective drug systems delivery have ultimately increased with the introduction of the block copolymer concept (3). Easy regulation of mechanical, chemical and physical properties was the greater advantage of synthetic polymers (4). PLGA nanoparticles are inspired by various kinds of medications counting anti-cancer drugs, hormones, anti-hypertensive drugs, vitamins and, macromolecules as antibodies, peptide (5). Polymers are also classified into two classes; natural polymers which known as 
a first class due to found in nature, for instance proteins such as collagen or carbohydrates such as cellulose. Potential biomaterials are all these polymers. In addition, naturally the polymers are existent like chitosan, present in arthropod exoskeletons; agarose which produced by algae and alginate derived from sea-weed, also a bilateral candidate for study $(4,6)$. Synthetic polymers including poly lactic acid (PLA), polystyrene and PLGA were called in the second class. There are various methods for PLGA preparation, such as single emulsion, double emulsion solvent evaporation, nanoprecipitation, drying and salting spray (7). Nanoprecipitation techniques are known to be an easy method for preparing nano drugs which distinguished by the low surfactants available, creating small sizes and low concentrations resulting of them. In addition, this technique provides perfect benefits for preparing polyethylene glycolpoly lactic acid-co-glycolic acid (PEG-PLGA) filled with low hydrophobicity active ingredients atoms encapsulated effectively that have been reported (8). In cardiovascular disease PLGA was also used, such that the coated polymer minimized the initial blast and helped to extend the release of the compounds (9). TPGS, water miscible forms of vitamin $\mathrm{E}$, is consist of a hydrophilic PEG chain matched with a hydrophobic vitamin $\mathrm{E}$ part (10). It displays wonderful drug delivery capability according to special amphiphilic structures. Additional researches, it has been proven that TPGS show excessive potential in over-coming multiple drug resistance (MDR) tumor for the P-glycoprotein (P-gp) inhibition, and selective anti-cancer outcome (11). TPGS can simply conjugate with polymers, or therapeutic agents to procedure TPGS based on polymers, or pro-drug. The co-administered ketamine aid two purposes: reducing the advancement of analgesic tolerance to the strong opioid and relieves neuropathic pain as it is strong N-methyl-Daspartate (NMDA) antagonists (12). Ketamine is a nonbarbiturate anesthetic, a short-acting, makes dissociated state with un-conscious patients, while it seems to be wakeful, and does not sense pain. Dissociative anesthesia offers amnesia, fixity and sedation. In addition, it is considered a potent bronchodilator so that safely to use with asthmatic patient, or cardiogenic, or hypovolemic shocks. On the other hand, it is used with caution with hypertensive patients or with stroke due to the drug is lipophilic passing rapidly to the brain. The coadministration of ketaminexylazine $(\mathrm{kx})$ is a preferable choice for injecting rabbits' regimen with anesthetic surgery (13). The publicity of ketamine-xylazine is mostly due to supplemental action, analgesic effect, relaxation of muscle and improve sedation. Safety anesthesia can be utilized without needed expert tools (14). As a result, the current project is aimed to find the best polymers for loading XK with lowering the dose level that should be more safety, healthy and yielded surgical tolerance for performing surgical interventions in rabbits.

\section{Materials and methods}

PLGA 50:50 (PURASORB PDLG 5010), Vitamin E TPGS National Formulary (NF) Grade, xylazine and ketamine were dissolved in Dimethyl Sulfoxide (DMSO). Nano-particles prepared according to the nano-precipitation method (15) including organic steps alteration of percentages of minh and organic solvent. An organic solution of PLGA $10 \mathrm{mg}$, liquefied in $4 \mathrm{ml}$ of DMSO and xylazine and ketamine $(1 \mathrm{mg})$ dissolved in $1 \mathrm{ml}$ of DMSO, then drug added slowly to PLGA under high vortex to form $5 \mathrm{ml}$ of organic phase. Aqueous phase prepares by $0.03 \%$ vitamin E TPGS solution $20 \mathrm{ml}$, distinct $\mathrm{w} / \mathrm{v}$, organic phase was added slowly to aqueous phase under high vortex then transfer solution to probe sonication for 5 minutes. The suspension collected was filtered to discard any precipitate then centrifuged at 14000 $\mathrm{rpm}$ at $4^{\circ} \mathrm{C}$ Sorvall RC 5 Plus to discard any precipitate. The free drug was separated in the supernatant portion and the pellet collected then washed 3-4 times with deionized water and lyophilized for two days to produce a free-flowing powder. Empty PLGAs have been produced in conjunction with the same process as before (16) (Figure 1).
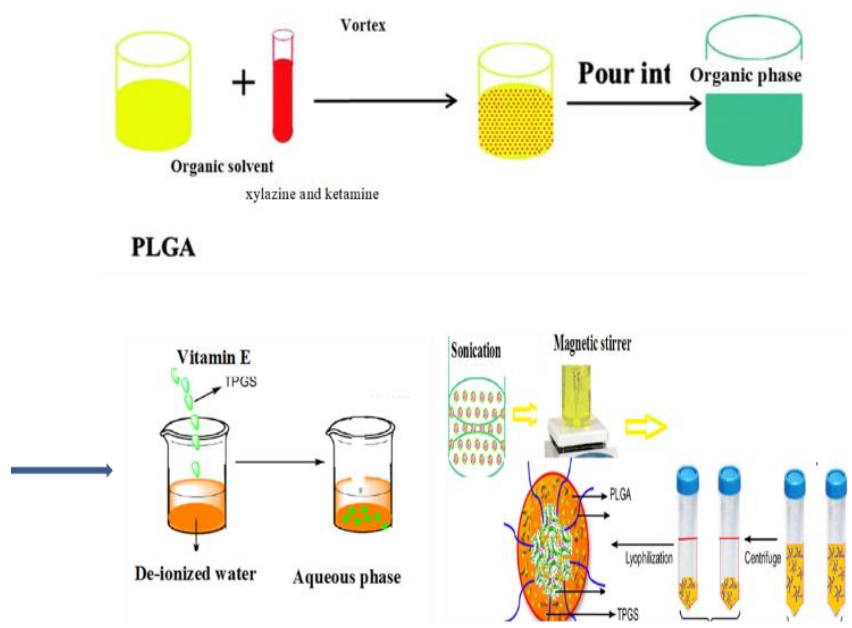

Figure 1: Show schematic of using our sequential nanoprecipitation method to fabricate ketamine-xylazine loaded polymeric nanoparticles. Suspension mixture containing ketamine-xylazine loaded by PLGA-TPGS. The scale bars are $280 \mathrm{~nm}$.

\section{Animal study}

The study was done on 15 adult local breed male rabbits, separated into 3 equivalent intramuscular injection groups in a single syringe. Group 1 injected with cocktail from ketamine $30 \mathrm{mg} / \mathrm{Kg}$ B.W and xylazine $10 \mathrm{mg} / \mathrm{Kg} \mathrm{B.W}$. Group 2 was infused with PLGA-TPGS loaded with ketamine $30 \mathrm{mg} / \mathrm{Kg}$ B.W and xylazine $10 \mathrm{mg} / \mathrm{Kg}$ B. Group 3 was injected with PLGA-TPGS loaded with ketamine 15 $\mathrm{mg} / \mathrm{Kg}$ B.W and xylazine $5 \mathrm{mg} / \mathrm{Kg}$ B.W. 
The following physiological parameters were analyzed, including: heart rate, respiratory rate, level of muscle relaxation, initiation of operation and anesthesia levels before administration of drugs at time 0 then 10, 30, 60 minutes after administration of the drug, anesthesia induction, surgical anesthesia and recovery time were also reported (Figure 2) (17,18).

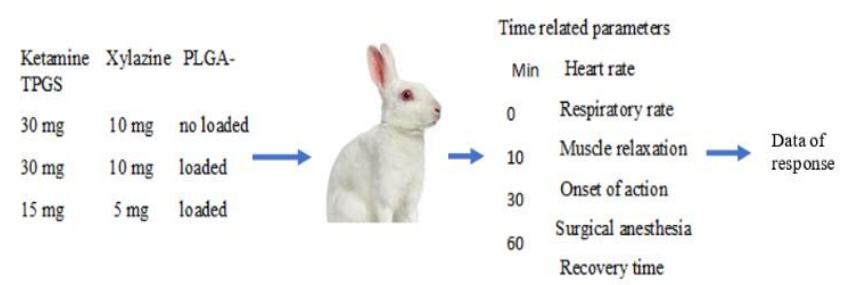

Figure 2: Show the three groups and physiological parameters analyzed.

\section{Statistical analysis}

The present study data were analyzed utilizing SPSS version 19 software. all outcome parameters are presented as mean + se. differences between quantitative data were analyzed using one-way ANOVA, followed by turkey's test. $\mathrm{P}$ - a value less than 0.01 is statistically significant for all data shown in our results.

\section{Result}

\section{Characterization of ketamine-xylazine nanoparticles drug}

Based on nanoprecipitation technique, we advanced ketamine-xylazine catalog loaded (TPGS-PLGA) nanoparticles to control the drug release profile and side effect of a large dose. For the preparation of high ketamineloaded polymer TPGS -PLGA nanoparticles, the same mass of ketamine and xylazine-TPGS-PLGA were dissolved in a solvent mixture of DMSO. Using our TPGS-PLGA method, ketamine precipitated to form uniform ketamine-xylazine nanoparticles. The scanning electron microscope (SEM) image shows a rounded shape particle, and the formulation size of ketamine-xylazine nanoparticles was $280 \mathrm{~nm}$ (Figures 3).
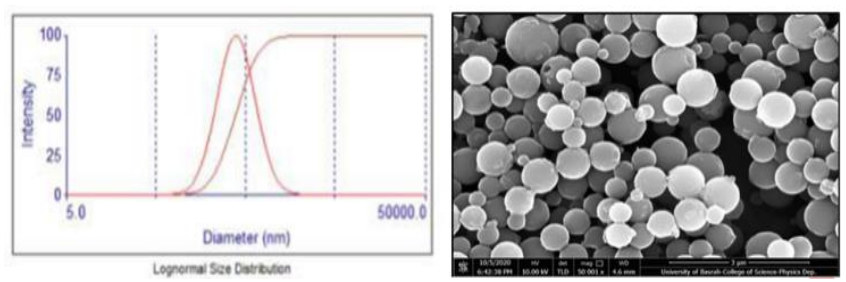

Figure 3: Show zeta sizer of ketamine and xylazine loaded by PLGA-TPGS, and SEM image shows a rounded shape particle.
Effect of ketamine-xylazine nanoparticles on heart rate

There was no-significantly difference, $\mathrm{P} \leq 0.05$ between group 1 and 3 in the heart rate within $0,10,30$ and 60 minutes. Moreover, PLGA loaded ketamine-xylazine showed a significant reduction of heart rate under normal level to recorded mean value $185.00 \pm 4.76$ and $190.80 \pm 10$ at 30 and 60 minutes respectively for group 2 that received complete dose than compared with half dose $15 \mathrm{mg}$ Ketamine and $5 \mathrm{mg}$ Xylazine filled with PLGA-TPGS that still mimic to reference dose cocktail. In addition, there were no-significantly differences $\mathrm{P} \leq 0.05$ between all groups of study at 0 and 10 minutes (Figure 4).

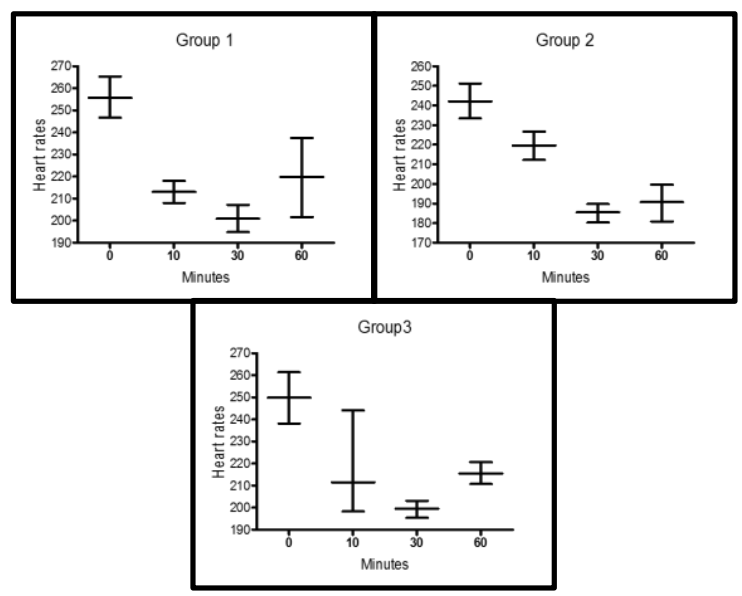

Figure 4: Show the heart rate within $0,10,30$ and 60 minutes in the three groups.

\section{Effect of ketamine-xylazine nanoparticles on respiratory rate}

Our result showed that there were no-significantly differences $\mathrm{P} \leq 0.05$, between groups 1,2 and 3 in the respiratory rate within $0,10,30$ and 60 minutes. Moreover, PLGA loaded Ketamine-Xylazine showed no significant reduction of respiratory rate to recorded mean value 162.40 $\pm 10.83,165.60 \pm 5.32$ and $175.60 \pm 6.79$ at $60 \mathrm{~min}$ respectively (Figure 5).

\section{Role of Ketamine-Xylazine nanoparticles on muscle relaxant}

Our result in table 1 showed there was no significant differences between group 1, 2 and 3 in the degree of muscle relaxant within 0 minutes, but there was a significant difference in G2 comparing with G1 and G3. Degree of muscle relaxant within 10, 20- and 30-minutes show there were no significant differences between G1 and G3. The present study showed that Ketamine-Xylazine nanoparticles appear significant differences of increasing surgical anesthesia at animal received nanoparticle at complete dose in $\mathrm{G} 2$ as well as half dose but there was no-significantly differences $\mathrm{P} \leq 0.05$, between group $\mathrm{G} 1$ and $\mathrm{G} 3$ in the degree 
of surgical anesthesia as well as recovery time was elevated in G1 group. Although delay onset of action in nano drug was very clear depend on release the drug from PLGA, but after short time of releasing them from PLGA, it was enough to induce pharmacological action in pulsatile manner (Figure $6)$.

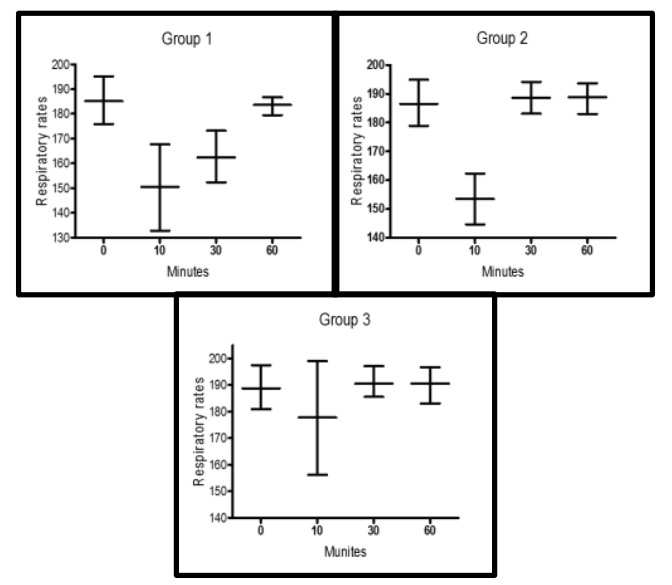

Figure 5: Show the respiratory rate within $(0,10,30$ and 60$)$ minutes in three groups.

Table 1: Show the degree of muscle relaxant within $0,5,10$, 20 and 30 minutes in all anesthetized groups

\begin{tabular}{lccc}
\hline \multirow{2}{*}{$\begin{array}{l}\text { Time } \\
\text { minutes) }\end{array}$} & \multicolumn{3}{c}{ degree of muscle relaxant } \\
\cline { 2 - 4 } & Group 1 & Group 2 & Group 3 \\
\hline 0 & \pm & \pm & \pm \\
5 & + & ++ & + \\
10 & + & ++ & + \\
20 & ++ & +++ & ++ \\
30 & ++ & +++ & ++ \\
\hline
\end{tabular}

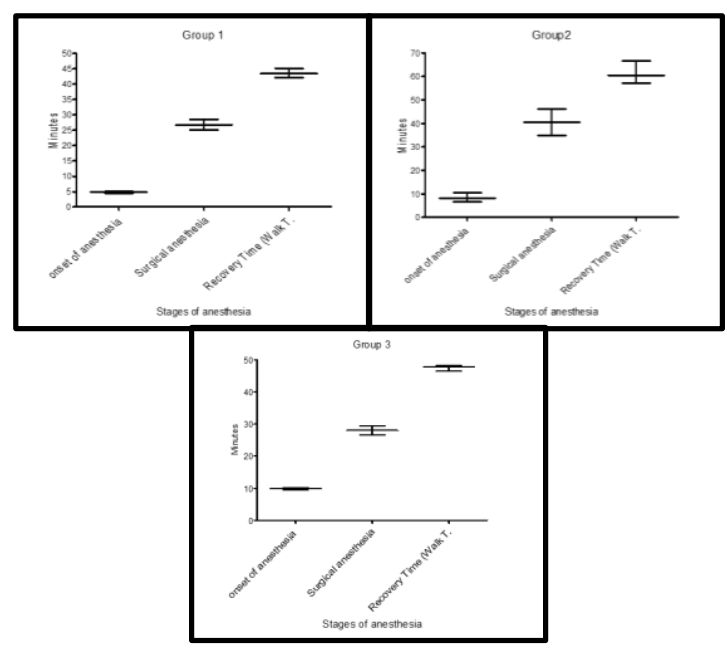

Figure 6: Show the onset of action, surgical anesthesia and recovery time in the three groups of anesthesia.

\section{Discussion}

Nanoparticles of around preparation of high ketamine loaded polymer TPGS -PLGA nanoparticles, using our TPGS-PLGA method, ketamine precipitated to form uniform ketamine-xylazine nanoparticles. The SEM image shows rounded shape of particles and the formulation size of particles of ketamine-xylazine nanoparticles was $280 \mathrm{~nm}$, which is optimal for the capacity of nanoparticles to be used after intramuscular injection. Our study used a drug-polymer ratio of 1:10, which is in line with the findings stated by Gaonkar et al. (19) who proved that the 1:10 ratio is ideal for a garcinol loading drug delivery device for PLGA rather than $1: 20$, and for drug loading (DL) and encapsulation efficiency (EE). The technique used here focuses on the synthesis of vitamin E TPGS nanoparticles as the emulsifying agent and DMSO as a solvent. Our analysis has shown that PLGA decreases the size of nanoparticles and inhibits aggregation and sedimentation of nanoparticles. In addition, the cell absorption and delivery restriction in the body due to the mononuclear phagocytic system tag decreased and the drug size of more than $1000 \mathrm{~nm}$ expelled (20). Ketamineencapsulated PEG-PLGA nanoparticles recorded mean value $107.4 \mathrm{~nm}$ with highly perfect encapsulation efficiency reach to $71.8 \%$ after utilized of nanoprecipitation method, moreover noted that a sustained-release of drug persist for nearly 21 in vitro and 5 day in mice. Therefore, a prolonged period of analgesia, it may be promise to control cancer or accidental sever pain is an area of future investigation.

There was no effect of xylazine-ketamine loading TPGSPLGA on the respiratory rate, on the other side, nanoparticles reduced full-dose heart rate relative to ketamine-xylazine nanoparticle and reference ketamine-xylazine. In our study, the development of ketamine-xylazine analgesia is compatible with the results of related studies. However, several workers documented a lack of analgesia in all the rabbits tested, including using higher doses of ketaminexylazine than the doses used in our research (16). Our data revealed that there are no-significantly differences, $\mathrm{P} \leq 0.05$, between group 1 and 3 in the heart rate within $0,10,30$ and 60 minutes. Moreover, PLGA loaded ketamine-xylazine showed a significant reduction of heart rate under normal level, ketamine increases cardiac output, blood pressure, central venous pressure. Cardiac stimulant characteristics support good induction agent for hypovolemic patient. Ketamine increases sympathetic outflow in the central nervous system, leading to activation of the heart with elevation of blood pressure and cardiac output. In rats, coinjection of ketamine with fentanyl, blocking target receptors channels in the spinal cord which can result in adequate analgesia by reducing analgesic tolerance and increasing pain relief (21). PLGA nanoparticles promoted by three factors includes, polymer degradation, internal-mass transfer, and external-diffusion. On the fundamental of our present data, the external-diffusion and internal-mass 
transfer likely limit the extent of ketamine-xylazine release and polymer degradation is the major factor that control the release afterward (22).

\section{Conclusion}

PLGA loaded with ketamine-xylazine demonstrated suitable polymer for developing drug delivery for general anesthesia regimen in rabbits. finally, the protocol created an excellent anesthetic combination for induction and maintenance of general anesthesia, it can be used in the future after conducting many researches to develop it in performing surgeries with local and general anesthesia.

\section{Acknowledgments}

I would like to express thanks to College of Veterinary Medicine, Al-Qassim Green university in Iraq for supporting the present work.

\section{Conflict of interest}

The authors declare that no conflict of interest exists.

\section{Reference}

1. Benabid FZ, Zouai F. Natural polymers: Cellulose, chitin, chitosan, gelatin, starch, carrageenan, xylan and dextran. Algerian J Natural Prod. 2016;4(3):348-357. DOI: 10.5281/zenodo.199036

2. Biondi M, Ungaro F, Quaglia F, Netti PA. Controlled drug delivery in tissue engineering. Advan Drug Delivery Rev. 2008;60(2):229-242. DOI: 10.1016/i.addr.2007.08.038

3. Kapoor DN, Bhatia A, Kaur R, Sharma R, Kaur G, Dhawan S. PLGA: a unique polymer for drug delivery. Therap Delivery. 2015;6(1):41-58. DOI: $10.4155 /$ tde. 14.91

4. Sampath U, Ching Y, Chuah C, Sabariah J, Lin P-C. Fabrication of porous materials from natural/synthetic biopolymers and their composites. Materials. 2016;9(12):991-1023. DOI: 10.3390/ma9120991

5. Uskokovic D, Stevanovic M. Poly(lactide-co-glycolide)-based micro and nanoparticles for the controlled drug delivery of vitamins. Cur Nanosci. 2009;5(1):1-14. DOI: 10.2174/157341309787314566

6. Ahmed S, Ikram S. Chitosan and its derivatives: a review in recent innovations. Inter J Pharmaceut Sci Res. 2015;6(1):14-30. DOI: 10.13040/IJPSR.0975-8232.6

7. Samadi N, Abbadessa A, Di Stefano A, van Nostrum CF, Vermonden T, Rahimian S, Teunissen EA, van Steenbergen MJ, Amidi M, Hennink WE. The effect of lauryl capping group on protein release and degradation of poly (d,1-lactic-co-glycolic acid) particles. J Controlled Release. 2013; 172(2): 436-443. DOI: 10.1016/j.jconrel.2013.05.034

8. Almoustafa H A, Alshawsh MA, Chik Z. Technical aspects of preparing PEG-PLGA nanoparticles as carrier for chemotherapeutic agents by nanoprecipitation method. Inter $\mathbf{J}$ Pharmaceut. 2017;533(1):275-284. DOI: 10.1016/j.ijpharm.2017.09.054

9. Jokerst JV, Lobovkina T, Zare RN, Gambhir SS. Nanoparticle PEGylation for imaging and therapy. Nanomed. 2011;6(4):715-728. DOI: $10.2217 / \mathrm{nnm} .11 .19$

10. Nejres AM, Ali HK, Behnam SP, Mustafa YF. Potential effect of ammonium chloride on the optical physical properties of polyvinyl alcohol. Systematic Rev Pharm. 2020;11(6):726-732. DOI: 10.31838/srp.2020.6.107
11. Soni K. Targeted delivery of drug combinations via nanocarriers for cancer treatment [ $\mathrm{PhD}$ dissertation]. Nebraska: University of Nebraska, Graduate College, Department of Pharmaceutical Sciences; 2017. 28$114 \mathrm{p}$.

12. Gupta A, Devi LA, Gomes I. Potentiation of $\mu$-opioid receptormediated signaling by ketamine. J Neurochem. 2011;119(2):294-302. DOI: 10.1111/j.1471-4159.2011.07361.x

13. Wellington D, Mikaelian I, Singer L. Comparison of ketamine-xylazine and ketamine-dexmedetomidine anesthesia and intraperitoneal tolerance in rats. J Am Asso Lab Anim Sci. 2013;52(4):481-487. [available at]

14. Jamal MA, Ahmed AM, Tahir M, Ashraf M, Sattar A, Ghafoor A, Munir S, Ahmed I, Hussain M, Riaz A. Safety and efficacy of ketamine xylazine along with atropine anesthesia in BALB/c mice. Brazilian $\mathrm{J}$ Pharmaceut Sci. 2019;55(1):1-6. DOI: 10.1590/s217597902019000317231

15. Jasim AM, Hasan HF, Awady MJ. Preparation of vorapaxar loaded with vitamin E TPGS and PVA emulsified PLGA nanoparticles i0n vitro studies. Res J Pharm Technol. 2019;12(9):4503-4510. DOI: 10.5958/0974-360X.2019.00776.5

16. Hirano S, Bovi M, Romeo A, Guzzo F, Chiamulera C, Perduca M. Ketamine nano-delivery based on poly-lactic-co-glycolic acid (PLGA) nanoparticles. Appl Nanosci. 2018;8(4):655-663. DOI: 10.1007/s13204-018-0765-1

17. Abass BT, Al-Hyani OH, Al-Jobory AKH. Anesthesia in xylazine premedicated donkeys with ketamine and ketamine-propofol mixture: A comparative study. Iraqi J Vet Sci. 2007;21(1):117-123. DOI: 10.33899/ijvs.2007.5633

18. Mousa YJ, Mohammad FK. The analgesic efficacy of xylazine and dipyrone in hydrogen peroxide-induced oxidative stress in chicks. Iraqi J Vet Sci. 2012;26(2):69-76. DOI: 10.33899/ijvs.2012.67444

19. Gaonkar RH, Ganguly S, Dewanjee S, Sinha S, Gupta A, Ganguly S, Chattopadhyay D, Chatterjee Debnath M. Garcinol loaded vitamin E TPGS emulsified PLGA nanoparticles: preparation, physicochemical characterization, in vitro and in vivo studies. Sci Rep. 2017;7(1):1-14. DOI: 10.1038/s41598-017-00696-6

20. Han FY, Liu Y, Kumar V, Xu W, Yang G, Zhao C-X, Woodruffa TM, Whittaker AK, Smith, MT. Sustained-release ketamine-loaded nanoparticles fabricated by sequential nanoprecipitation. Inter $\mathbf{J}$ Pharmaceut. 2020;581(1):1-7. DOI: 10.1016/j.ijpharm.2020.119291

21. Twegh MA-E, Hamzah KJ, Jasim AM, Mohammed QA. Protective role of vitamin-TPGS to overcome oxidative stress induced by dipping of sheep with cypermethrin. Plant Arch. 2020;20(1):1105-1109. [available at]

22. Han FY, Whittaker AK, Howdle SM, Naylor A, Shabir-Ahmed A, Zhang C, Smith MT. Formulation of bioerodible ketamine microparticles as an analgesic adjuvant treatment produced by supercritical fluid polymer encapsulation. Pharmaceut. 2018;10(4):264-278. DOI: 10.3390/pharmaceutics10040264 
الأدوية. هدفت الدراسة على استخدام بوليمر توكوفيرول بولي إيثيلين

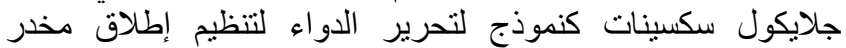
الزيلازين-كيتامين من أجل تقليل الجر عة العلاجية وتجنب التبر الآثار الجانبية

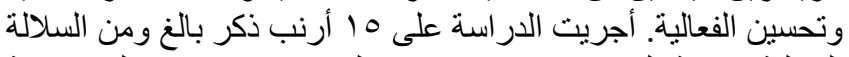

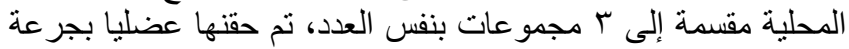

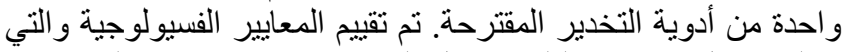

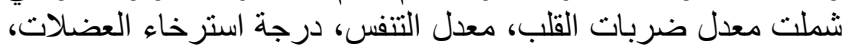



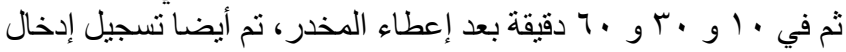

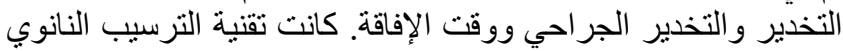
هي الطريقة المثلى لتحضير حجم الجسيمات الصغيرة الصيرة وكذللك تقليل

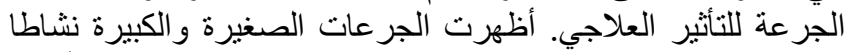

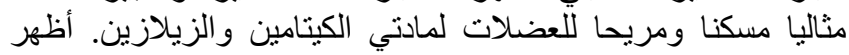

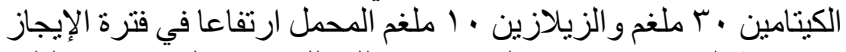

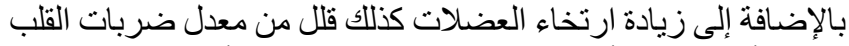

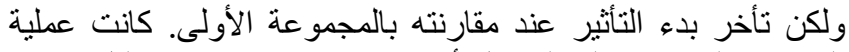

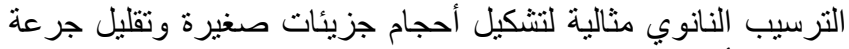



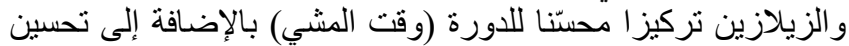

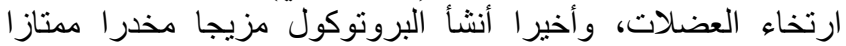

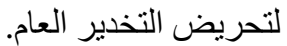

\section{دور بولي حمض اللاكتيك_كو-جليكوليك / توكوفيرول بولي إيثلين جلايكول سكسينات

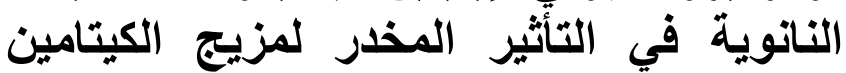 والزيلازين في ذكور الأرانب البيضاء ليزي}

عمر عادل بدر'، عدنان منصور جاسمّ، محمد جاسم جواد" وحسين

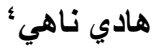

'فرع الجراحة وعلم تتاسل الحيوان، كلية الطب البيطري، جامعة الكوانة

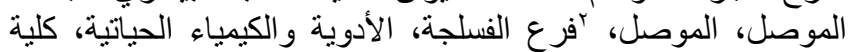

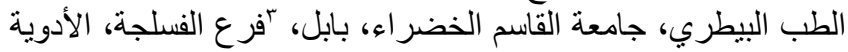

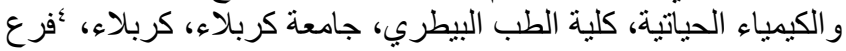

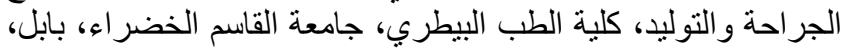
العراق



اعتمد استخدام توكوفيرول بولي إيثيلين جلايكول سكسينات من قبل إدارة الغذاء و الدو اء كمساعد آمن وعلى نولى نطاق و اسع في أنظمة توصيل 